\title{
A Quantitative Polymerase Chain Reaction Test to Enumerate Leukocytes in Allograft Tissue and the Implications for Donor Eligibility Testing
}

\author{
Cari E. Podzemny ${ }^{a}$ Matthew D. Brenton ${ }^{a}$ Scott A. Brubaker ${ }^{b}$ \\ Russell C. Marians ${ }^{\text {a }}$ \\ ${ }^{a}$ LABS, Inc., Centennial, Colo., and ${ }^{b}$ American Association of Tissue Banks, McLean, Va., USA
}

\section{Key Words}

Human T-lymphotropic virus · Donor eligibility · Leukocyte . Quantitative polymerase chain reaction · Allograft

\begin{abstract}
A country-to-country analysis of infectious disease screening requirements for donated tissues or cells reveals they are not often harmonized. Transmission of one such infectious disease, human T-lymphotropic virus (HTLV), is related to the transfer of HTLV-infected, viable leukocytes of sufficient number. The ability to characterize allograft tissue as being absent of leukocytes, or containing relatively few leukocytes, by using a specific test has not been previously investigated. A quantitative polymerase chain reaction (qPCR) test was developed to interrogate protein tyrosine phosphatase, receptor type C (PTPRC) gene expression in tissue samples and was able to determine the number of leukocytes present in a tissue. The impact of a qualified leukocyte tissue testing method should be significant and lead to changes in donor eligibility regulations in certain countries. Human leukapheresis samples were used as a control to establish the amount of PTPRC in leukocytes. That value was used as a comparator to determine the number of leukocyte equivalents in tissues of interest. The qPCR test measured tissue leukocyte equivalents and
\end{abstract}

This work was performed at LABS, Inc.

\begin{tabular}{|c|c|}
\hline KARGER & $\begin{array}{l}\text { (c) } 2013 \text { S. Karger AG, Basel } \\
1422-6405 / 13 / 1983-0221 \$ 38.00 / 0\end{array}$ \\
\hline $\begin{array}{l}\text { E-Mail karger@karger.com } \\
\text { www.karger.com/cto }\end{array}$ & $\begin{array}{l}\text { This is an Open Access article licensed under the terms of the } \\
\text { Creative Commons Attribution-NonCommercial 3.0 Un- } \\
\text { ported license (CC BY-NC) (www.karger.com/OA-license), } \\
\text { applicable to the online version of the article only. Distribu- } \\
\text { tion permitted for non-commercial purposes only. }\end{array}$ \\
\hline
\end{tabular}

the results were consistent with the relative abundance of leukocytes predicted for each tissue. Using QPCR to calculate leukocyte equivalents based upon PTPRC gene expression can be successfully employed to estimate the number of leukocytes in a tissue or allograft. This method could be used as a screen to rule out tissues that do not meet the criteria of being leukocyte rich and, therefore, do not need direct HTLV testing.

(c) 2013 S. Karger AG, Basel

\begin{tabular}{ll}
\hline Abbreviations used in this paper \\
\hline cDNA & $\begin{array}{l}\text { complementary deoxyribonucleic acid } \\
\text { cycle threshold }\end{array}$ \\
Ct & US Food and Drug Administration \\
FDA & glyceraldehyde-3-phosphate dehydrogenase \\
GAPDH & human cells, tissues, and cellular and tissue-based \\
HCT/Ps & $\begin{array}{l}\text { products } \\
\text { human embryonic kidney }\end{array}$ \\
HEK & human T-lymphotropic virus \\
HTLV & antibodies to HTLV \\
HTLV Ab & human T-lymphotropic virus type 1 \\
HTLV-1 & human T-lymphotropic virus type 2 \\
HTLV-2 & $\begin{array}{l}\text { peripheral blood mononuclear cells } \\
\text { PBMCs }\end{array}$ \\
PBS & $\begin{array}{l}\text { phosphate-buffered saline } \\
\text { PTPRC }\end{array}$ \\
protein tyrosine phosphatase, receptor type C \\
qPCR & $\begin{array}{l}\text { quantitative polymerase chain reaction } \\
\text { ribonucleic acid }\end{array}$ \\
RNA & standard deviation \\
SD &
\end{tabular}

Dr. Russell C. Marians LABS, Inc. 6933-B S. Revere Parkway Centennial, CO 80112 (USA)

E-Mail Russell_marians@ @labs-inc.org 


\section{Introduction}

Human T-lymphotropic virus (HTLV) is a human retrovirus that primarily affects $\mathrm{T}$ lymphocytes, a prominent type of leukocyte, through integration of its genome with that of the host T lymphocyte. Specifically, human T-lymphotropic virus type 1 (HTLV-1) has an affinity predominantly for CD4 lymphocytes, while human T-lymphotropic virus type 2 (HTLV-2) predominantly infects CD8 lymphocytes [Lairmore and Fujii, 2005]. It is understood that transmission of disease could occur if a medical therapy uses a product of human origin that contains a sufficient number of viable leukocytes infected with HTLV [Okochi and Sato, 1985; Pennington et al., 2002]. Examples of such products and therapies could include blood for transfusion, peripheral blood stem cells for infusion, semen for transfer, and, possibly, certain tissue allografts for transplantation. Safety is achieved through tissue processing methods that successfully remove or destroy the viable cell type that mediates HTLV transmission. Storage of tissue before use can be for months to years and it has been hypothesized that lyophilized bone tissue stored longer than 15 days cannot transmit viral disease [Salvucci, 2011].

However, laws and regulations that govern cell and tissue banking relative to HTLV risk are not harmonized, and these requirements include expectations for infectious disease testing as well as screening the donor for communicable disease risks associated with certain behaviors, travel, and medical or family history. Regulations and guidance promulgated by the US Food and Drug Administration (FDA) for human cells, tissues, and cellular and tissue-based products (HCT/Ps) use 'rich in viable leukocytes' to describe a tissue type that is relevant for HTLV risk [US Department of Health and Human Services and Food and Drug Administration, 2004, 2007]. The 13th edition of the Standards for Tissue Banking of the American Association of Tissue Banks [2012] is in agreement with FDA requirements, as is Health Canada [2009] [Carmen et al., 2012; Canada Standards Association, 2012]. In an ever changing global demographic, it is problematic for a screening approach to rely on properly identifying 'areas' that would be, without a doubt, considered as 'high prevalence' for this disease.

Requirements for screening and testing donors often do not consider a well-established criterion that transmission of HTLV is known to require the transfer of sufficient numbers of viable, HTLV-infected leukocytes [Pennington et al., 2002]. Studies supporting this notion are based on transfusion of blood and blood products which repre- sent a worst-case scenario, compared to tissue allografts, for exposure to the large quantity of viable leukocytes contained in a unit of transfused, unfiltered, or short-stored red blood cells or whole blood. In the case of transfusion of red blood cell units, investigations have reported that the presence of a minimum number of HTLV-contaminated, viable leukocytes may be required for seroconversion to occur [Okochi and Sato, 1986; DePalma et al., 1993]. There has been only one recorded instance of HTLV transmission from a tissue transplant. In that case, unprocessed cancellous bone from a living donor femoral head was used in surgery after it had been stored frozen for 30 days. The recipient developed antibodies and tested seropositive for HTLV but did not develop disease during follow-up [Sanzen and Carlsson, 1997].

In Canada and the USA, tissue establishments are required only to test donors of viable, leukocyte-rich cells or tissues for antibodies to HTLV (HTLV Ab). The FDA designation of HCT/Ps that are rich in viable leukocytes is based on their status at the time of recovery, even if later processing might remove leukocytes. Such viable, leukocyte-rich tissues include, but are not limited to, semen and hematopoietic progenitor/stem cells. Cells and tissues that are not considered to be rich in viable leukocytes can be released for distribution without testing the donor for HTLV Ab or screening for HTLV risk. However, many tissue donors are tested for HTLV Ab by US tissue banks, so finished tissue allografts can be distributed to countries in Europe that require this test [Hartill and Brubaker, 2011]. Requiring a donor screening test increases health care costs and can cause confusion in the infrequent event that the test is positive but the tissue allografts from the donor do not contain leukocytes.

To aid authorities in better understanding the characterization of tissue allografts and any risk relative to HTLV, this study was undertaken to explore the feasibility of testing tissue allografts for the presence of leukocytes without a need to determine leukocyte viability. The hypothesis was that the number of leukocytes in allograft tissue was indeed very low (leukocyte poor). For this study the number of leukocytes in a test tissue was evaluated using real-time polymerase chain reaction (qPCR). We took advantage of CD45, encoded by the protein tyrosine phosphatase, receptor type C (PTPRC) gene, for use as an indicator of leukocytes because its expression is restricted to that subset of cells. Human leukapheresis samples were used as a positive control to establish a cutoff for PTPRC positivity. Using the criteria established in this study, one can determine the number of leukocytes present in a tissue of interest. 


\section{Materials and Methods}

Tissues

The leukocytes used in this study were remnant leukapheresis samples obtained from human donors. Use of remnant clinical samples is permitted under Guidance on Informed Consent for in vitro Diagnostic Device Studies Using Leftover Human Specimens that Are Not Individually Identifiable, OMB No. 0910-0582. The donor samples were blinded and were a mix of allogeneic and autologous stem cells from healthy donors and leukemia patients. Leukocyte samples were confirmed to be $100 \%$ CD $45+$ by flow cytometry (data not shown). Leukapheresis samples were kept at $2-8^{\circ} \mathrm{C}$ and were processed within 4 days of collection. Amniograft (BioTissue Incorporated) samples were stored for 1-3 month in DMEM/glycerol (1:1) with ciprofloxacin and amphotericin B at -77 to $-83^{\circ} \mathrm{C}$. Corneas (Rocky Mountain Lions Eye Bank) were stored in Optisol-GS (Chiron) or Life $4^{\circ} \mathrm{C}$ (Numedis) for 1-4 days at $2-8^{\circ} \mathrm{C}$. Fresh skin grafts (The Living Legacy Foundation) were either processed immediately or stored in RNAlater (catalog No. 76106; Qiagen) until use. Prior to processing, excess sclera was removed from the corneas while the periscleral vascular region was preserved for analysis. Peripheral blood mononuclear cells (PBMCs; HemaCare Corporation Donor Unit No. W313712016791) obtained from a healthy blood donor were employed as a positive control, using the same extraction method as for the leukapheresis samples. Ribonucleic acid (RNA) commercially prepared from lung, spleen, and brain (catalog No. 636524, 636525 , and 636530, respectively; Clontech) was used for proof of concept for representative tissues.

\section{RNA Preparation and Complementary Deoxyribonucleic} Acid Synthesis

Total RNA was isolated from $6 \times 10^{6}$ leukocytes $(n=28$ different donors) and from cornea $(\mathrm{n}=14)$, skin $(\mathrm{n}=15)$, and amnion $(\mathrm{n}=15)$ using either an RNeasy Mini Kit (catalog No. 74104; Qiagen) or an AllPrep DNA/RNA/Protein Mini Kit (catalog No. 80004; Qiagen) according to manufacturers' directions, including the optional DNAse step. RNA quality as assessed using a BioAnalyzer (Agilent) was equivalent with both isolation methods. RNA quality from the leukapheresis samples was equivalent with both isolation methods (data not shown). All leukocyte samples met a minimum RNA concentration of $100 \mathrm{ng} / \mu \mathrm{l}$. The concentration of RNA obtained from amnion and cornea tended to be much lower and a minimum requirement of $4 \mathrm{ng} / \mu \mathrm{l}$ RA concentration was used for these samples. RNA quantification and purity was tested using NanoDrop (Thermo Scientific) on all samples. Leukocytes, skin, and cornea were homogenized in a rotor-stator prior to extraction. Amniografts were homogenized using a ground glass homogenizer. Using the Promega GoScript Reverse Transcription System (catalog No. A5000), complementary deoxyribonucleic acid (cDNA) was synthesized from the RNA following manufacturer's instructions starting from $2 \mu \mathrm{g}$ RNA.

The sclera was removed from the cornea and discarded, but the periscleral vascular region was included. Before isolation, amnion and cornea samples were treated with $600 \mu \mathrm{l}$ RAlater RNA stabilization reagent (Qiagen) and then rinsed with an equal volume of phosphate-buffered saline (PBS) to improve sample handling. Skin samples were stored in $600 \mu \mathrm{l}$ RNAlater at -77 to $-83^{\circ} \mathrm{C}$ and then rinsed with an equal volume of PBS.

HTLV Screening of Allograft Tissue
Table 1. Results for leukocyte samples

\begin{tabular}{lllll}
\hline $\begin{array}{l}\text { Leukapheresis } \\
\text { samples, } \mathrm{n}\end{array}$ & Gene & $\mathrm{Ct} \pm \mathrm{SD}$ & $95 \% \mathrm{CI}$ & $\mathrm{Ct}$ ratio \\
\hline \multirow{2}{*}{28} & PTPRC & $19.21 \pm 0.66$ & 0.24 & \\
& GAPDH & $18.77 \pm 1.27$ & 0.47 & 1.03 \\
\hline
\end{tabular}

\section{Real-Time PCR}

To establish a threshold gene expression level of PTPRC from leukocytes, cDNA from $3 \times 10^{5}$ cells per sample was analyzed by qPCR. Samples were analyzed on a 7500 Fast DX Real-Time PCR System (Applied Biosystems). Reactions were multiplexed using the following assays from Life Technologies: PTPRC (FAM, cata$\log$ No. HS00894732_m1) and glyceraldehyde-3-phosphate dehydrogenase (GAPDH) (VIC, catalog No. 4326317E) using TaqMan Fast Advanced Master Mix (catalog No. 4444557). The ubiquitously expressed reference gene GAPDH was included in the analysis as a positive control. For each sample, $2 \mu \mathrm{lDNA}$ was used in a $20-\mu \mathrm{l}$ reaction. The $\mathrm{qPCR}$ were run under universal conditions. Cycling conditions were: $\left(95^{\circ} \mathrm{C}: 10 \mathrm{~min}\right)$; $\left(95^{\circ}: 15 \mathrm{~s}, 60^{\circ}: 1 \mathrm{~min}\right) \times$ 40 cycles.

\section{Analysis}

It was determined that $3 \times 10^{5}$ leukocytes yielded a cycle threshold (Ct) of 19.21. For each leukapheresis sample, $6 \times 10^{6}$ leukocytes were used for RNA isolation, from which $2 \mu \mathrm{g}$ RNA was converted into $2 \mu \mathrm{g}$ of cDNA:

Equation 1: $6 \times 10^{6}$ leukocytes $\div 2 \mu \mathrm{g}$ cDNA $=3 \times 10^{6}$ leukocytes per $\mu \mathrm{g}$ cDNA

Each qPCR utilized $0.1 \mu \mathrm{g}$ cDNA, or $3 \times 10^{5}$ leukocytes:

Equation 2: $3 \times 10^{6}$ leukocytes per $\mu \mathrm{g}=\mathrm{X} \div 0.1 \mu \mathrm{g} ; \mathrm{X}=3 \times 10^{5}$ leukocytes

The number of leukocytes present in a sample of unknown tissue was calculated by dividing the leukocyte standard value by $2^{-\Delta \mathrm{Ct}}$ (PCR is a $\log _{2}$ function because the amount of PCR product doubles with every additional PCR cycle):

Equation 3a: $\Delta \mathrm{Ct}=19.21-$ unknown $_{\mathrm{CtPTPRC}}$

Equation 3 b: $3 \times 10^{5}$ leukocytes $\div 2^{-\Delta \mathrm{Ct}}=$ leukocyte number

The final leukocyte load in tissues of interest was then calculated by adjusting for the amount of material used in a given $\mathrm{qPCR}$, where A equaled the fraction of tissue from which RNA was extracted, $B$ equaled the fraction of RNA used to generate $C D N A$, and $\mathrm{C}$ equaled the fraction of cDNA used as input for the qPCR:

Equation 4: leukocyte load = leukocyte number $\times \mathrm{A} \times \mathrm{B} \times \mathrm{C}$

\section{Results}

Key to making our study applicable to multiple laboratories using varying instrumentation and controls was determining the amount of PTPRC in leukocytes. As measured by our assay, the amount of PTPRC RNA in the reference set of $3 \times 10^{5}$ leukocytes ( $\mathrm{n}=28$ samples) was remarkably consistent: $\mathrm{Ct}=19.21 \pm 0.66$ (table 1 ). The 

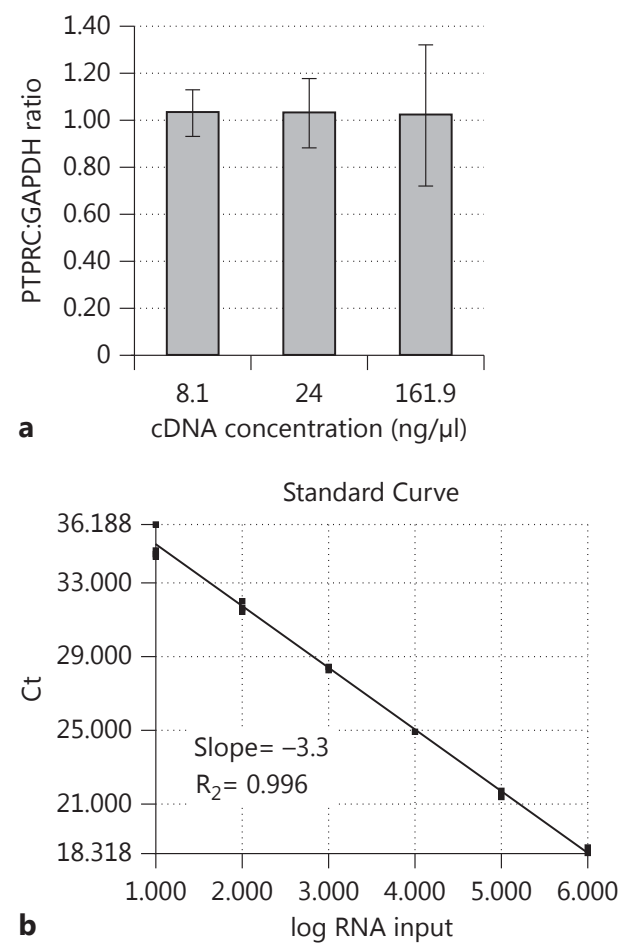

Fig. 1. Performance of the PTPRC assay. a cDNA from a single leukocyte sample was diluted to concentration levels approximating those typically observed from low-yield tissues (amnion and cornea). Diluted samples were then analyzed by qPCR. The relative abundance of PTPRC and GAPDH did not change as a function of the amount of cDNA used for the analysis. $\mathbf{b}$ A dilution series was run with cDNA pooled from 10 previously tested leukocyte samples. Sample No. 1 was run neat. The graph shows Ct vs. dilution. The assay was linear over 6 logs (full range of detection), showing that the assay is effective over a wide concentration range.

PTPRC:GAPDH ratios remained the same regardless of the amount of starting cDNA (fig. 1a), indicating that the assay functioned equally well over a wide range of cDNA input to the assay. The PTPRC assay performed well and was linear over 6 logs (fig. 1b).

To define the performance characteristics of our assay, mesenchymal stem cells known not to express PTPRC were combined with varying amounts of leukocytes (fig. 2). The lowest level of detection was found to be $0.5 \%$ leukocytes. This demonstrates that PTPRC qPCR can be used to detect a low level of leukocyte contamination in tissue samples.

To further qualify this assay as a viable method to determine the relative quantity of leukocytes in a tissue, it

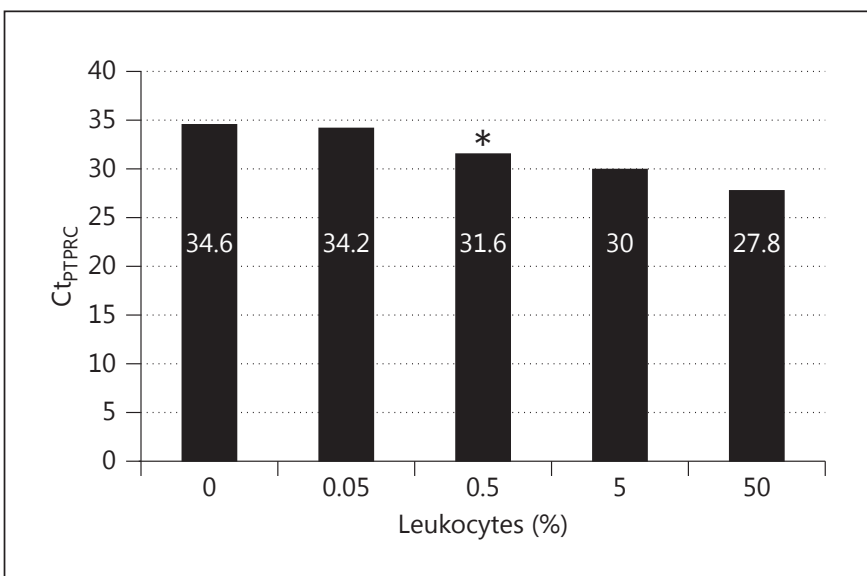

Fig. 2. PTPRC qPCR can detect low-level leukocyte contamination. The assay was run on a combination of leukocytes and mesenchymal stem cells, mixed at the indicated percentages $(n=3$ for each concentration; standard deviation marks are not visible within the data bars). The lower limit of detection was determined to be $0.5 \%$ leukocytes $\left[{ }^{*} \mathrm{p}<0.005\right.$, t test (paired, 2 -tailed) compared to $0 \%$ leukocytes].

Table 2. Tissue leukocyte equivalents

\begin{tabular}{lcc}
\hline Sample & Ct $_{\text {PTPRC }}$ & $\begin{array}{l}\text { Leukocyte equivalents } \\
\text { per qPCR reaction }\end{array}$ \\
\hline Leukocyte & 19.09 & 325,000 \\
PBMC & 19.37 & 268,000 \\
PBMC (commercial RNA) & 20.38 & 133,000 \\
Spleen & 23.07 & 20,700 \\
Lung & 24.06 & 10,400 \\
Brain & 30.02 & 167 \\
HEK cells & 37.05 & 0 \\
\hline
\end{tabular}

Table 3. Results of allograft tissues

\begin{tabular}{llrc}
\hline Sample & Replicates, $\mathrm{n}$ & $\mathrm{Ct}_{\mathrm{PTPRC}} \pm \mathrm{SD}$ & $\begin{array}{l}\text { Leukocyte equiva- } \\
\text { lents per tissue } \pm \mathrm{SD}\end{array}$ \\
\hline Skin & 16 & $28.8 \pm 1.33$ & $\begin{array}{c}26,009 \pm 45,220 \\
\text { Cornea }\end{array}$ \\
Amnion & 18 & $30.24 \pm 1.93$ & $1,453 \pm 1,840$ \\
& $38.48 \pm 0.67$ & 0 \\
\hline
\end{tabular}

was tested against commercially available total RNA from lung, spleen, and brain. Human embryonic kidney (HEK) cells were included as a negative control. As a positive control, PBMCs obtained from a healthy donor were used as starting material for our assay, which also served to verify that reference leukapheresis samples were an appropriate standard. As shown in table 2, the tissue leuko- 
cyte equivalents in order of highest to lowest were spleen $\left(2 \times 10^{4}\right)$, lung $\left(1 \times 10^{4}\right)$, brain $(200)$, and HEK cells (1). These results were consistent with the relative abundance of leukocytes predicted for each tissue.

This proof of concept was further tested against a larger sample size of commonly used allograft tissues: skin, cornea, and amnion (table 3). The allograft samples all had a wider variation of PTPRC Ct values and consequently more variability in leukocyte loads than the reference leukocyte sample set, reflecting donor-to-donor variability of leukocyte levels in these tissues. All test tissues were found to have fewer leukocytes than the reference material. Leukocounts estimated by our method matched FDA guidance inferring that cornea and skin are leukocyte-poor tissues, a designation that our assay demonstrated could also be applied to amnion.

\section{Discussion}

This study was undertaken to further justify that the characterization of tissue allografts, with regard to the presence of leukocytes, is the prominent relevant factor to properly assess the risk of HTLV in tissue transplantation. A novel qPCR test against the PTPRC gene, which is specifically expressed in leukocytes, was evaluated for use in determining the number of leukocytes in an allograft tissue [Kaplan et al., 1990]. Importantly, the test cannot address viral load, as the analyte is not part of the viral genome. Tissues validated to be leukocyte poor could be safely transplanted regardless of donor HTLV status. Although a rare event, when present in a high enough quantity, leukocytes have been known to transmit virus to previously uninfected individuals through unfiltered blood and platelet transfusion [Manns et al., 1992]. To protect the population from the potential of HTLV transmission, the FDA defined common allograft tissues as leukocyte rich or leukocyte poor and required HTLV testing for donors of viable, leukocyte-rich tissues.

An important piece of this study was to establish a $\mathrm{Ct}$ cutoff from a representative sample set of leukocytes. Leukapheresis samples that had been previously tested for white blood cell count and PTPRC expression by flow cytometry were chosen as a source of leukocytes. Twentyeight samples were tested and their Ct results were averaged to give us a reference cutoff of $19.21 \pm 0.66$ per $3 \times$ $10^{5}$ leukocytes (table 1 ). This cutoff was challenged using an alternative leukocyte source (commercially available PBMCs from a healthy donor). Results obtained from the third party PBMC sample were consistent with our refer- ence set of leukocytes, allowing us to establish a cutoff that gave us a base number against which all tissue $\mathrm{Ct}$ measurements of leukocyte equivalents would be calculated (table 2).

Based on our study, qPCR can be used to calculate leukocyte equivalents in allograft tissue by assessing the level of PTPRC gene expression. One potential problem with this assay is the difficulty in obtaining RNA from various tissue sources. Amnion, for example, was more challenging to evaluate than skin or cornea for several reasons. The typical amnion sample was very small (4 $\mathrm{cm}^{2}$ ) and had relatively few cells, being approximately 3 cell layers thick, making high-yield RNA extraction difficult. A glass tissue grinder kept on ice increased extraction yields, yet this grinding method might not be applicable to other tissues, such as bone or heart valves. Vendors of commonly used RNA extraction kits often have special protocols that include pulverization or grinding prior to extraction in order to increase the yield and purity of the RNA isolated from hard or fibrous tissues. Once RNA is isolated, however, the downstream qPCR process should remain constant, regardless of tissue type. We found that, even with a low RNA yield, the model still worked using the PTPRC-to-GAPDH ratio as an internal control. Our test also made the assumption that the measured PTPRC signal was derived entirely from leukocytes present in the test tissue. It was possible that low-level PTPRC expression from the nonleukocyte cells within the test tissue contributed to the overall PTPRC signal observed. Our assay measured total RNA from all cell types present in the test article and did not exclude nonviable cells from analysis. Therefore, this screening assay reported a conservative leukocount and should be considered a worst-case estimate of viable leukocytes in a given tissue.

The PTPRC assay proved to be robust, giving consistent results across a number of different variables. Results were not influenced by the low RNA yield (fig. 1a), the test was linear over a wide concentration range (fig. 1b), and the assay was able to detect a low level of leukocyte contamination (fig. 2). Several tissues were targeted for proof of principle due to their expected leukocyte load. Spleen was used as an example of a tissue that, because it is a known lymphoid tissue, was expected to contain a large number of leukocytes. Lung was used because it should contain a moderate number of leukocytes which are in place to protect the body from airborne infection. Brain is not normally accessible to leukocytes due to the blood-brain barrier and was expected to contain very few leukocytes. Cultured HEK cells were used as a negative set 
of cells that would contain no leukocytes. Calculated leukocyte equivalent values were consistent with the relative abundance of leukocytes predicted for each tissue type by this method (table 2).

The PTPRC assay also performed well against allograft tissue, as shown in table 3. Due to their anatomy, the allograft tissues tested were expected to contain relatively few leukocytes. Amnion is made up of a stromal layer, a basement layer, and an epithelial layer of cells that is avascular, so consequently it should have no leukocytes. Cornea is mostly avascular and is made up of an endothelium, an epithelium, and collagen-rich membranes that should contain few, if any, leukocytes. The skin used in the study was split-thickness skin, where the dermis was discarded after being separated from the epidermis. Epidermis is known to have resident leukocytes which serve an important role in immune surveillance [Schon et al., 2003]. The number of leukocytes calculated for allograft tissues was highly variable, especially in skin, but it was consistently lower than the reference standard leukocytes: skin had the most leukocytes, amnion had the fewest, and cornea was intermediate. The rank order of tissue allografts by leukocyte quantity was as expected. Being exposed to the environment, skin was expected to have the highest leukocount. There were more leukocytes detected in cornea than we anticipated. We hypothesize, however, that the vast majority of corneal leukocytes were found in the vascular border between the cornea and sclera, a part that is not used for transplantation but was included in our analysis. Amnion was the most highly processed tissue tested. Therefore, it was not surprising that amnion had the fewest leukocytes of the allograft tissues.

Based upon this proof-of-concept study, we believe that our qPCR method can successfully be applied to a variety of allograft tissues to determine the presence and relative abundance of leukocytes in those tissues. The availability of such a qualified tissue test method should lead to changes in certain countries regarding tissue donor testing and screening requirements for HTLV. This will not only avoid costs associated with unnecessary testing, but it will also avoid confusion and misrepresentation.

\section{Acknowledgments}

We would like to thank our friends who provided tissue for this study: Eye Bank Association of America, Rocky Mountain Lions Eye Bank, BioTissue, and The Living Legacy Foundation. Members of the Scientific and Technical Affairs Committee of the American Association of Tissue Banks (AATB) graciously edited the manuscript prior to submission, as did several of our colleagues at LABS, Inc.: Chad Ronholdt and Jerry Niediznski. This study was partially funded by a grant from the Scientific and Technical Affairs Committee of the AATB.

\section{References}

American Association of Tissue Banks (2012) Stan- Kaplan, R., B. Morse, K. Huebner, C. Croce, Salvucci, J.T. (2011) Bone tissue, lyophilized and dards for Tissue Banking. McLean, AATB.

Canada Standards Association (2012) General Standard CAN/CSA Z900 Series: Cells, Tissues, and Organs for Transplantation and Assisted Reproduction 2003 with Update 2007. Sections 13.1.2(c), 13.2.2(d), 13.1.3(e), 14.2.6(a), 14.2.6.3(d), 17.2.2(d). CSA Group, Mississauga, Ontario, Canada.

Carmen, J., S.R. Burger, M. McCaman, J.A. Rowley (2012) Developing assays to address identity, potency, purity and safety: cell characterization in cell therapy process development. Regen Med 7: 85-100.

DePalma, L., N.L.C. Luban (1993) Transmission of human T-lymphotropic virus type I infection to a neonatal infant by transfusion of washed and irradiated red cells. Transfusion 33: 582-584.

Hartill, C., S.A. Brubaker (2011) Human Tissue Regulation: Fundamentals of EU Regulatory Affairs, Fifth Edition. Rockville, Maryland, RAPS.

Health Canada (2009) Guidance document: safety of human cells, tissues, and organs for transplantation. http://www.hc-sc.gc.ca/dhp-mps/ alt_formats/hpfb-dgpsa/pdf/brgtherap/cell/ cto_gd_ld-eng.pdf (accessed April 17, 2013). R. Howk, M. Ravera, G. Ricca, M. Jaye, J. Schlessinger (1990) Cloning of three human tyrosine phosphatases reveals a multigene family of receptor-linked protein-tyrosinephosphatases expressed in brain. Proc Natl Acad Sci USA 87: 7000-7004.

Lairmore, M.D., M. Fujii (2005) 12th International Conference on Human Retrovirology: HTLV and Related Retroviruses. Retrovirology 2: 61.

Manns, A., R.J. Wilks, E.L. Murphy, G. Haynes, J.P. Figueroa, M. Barnett, B. Hanchard, W.A. Blattner (1992) A prospective study of transmission by transfusion of HTLV-I and risk factors associated with seroconversion. Int J Cancer 51: 886-891.

Okochi, K., H. Sato (1985) Adult T-cell leukemia virus, blood donors and transfusion: experience in Japan. Prog Clin Biol Res 182: 245-256.

Okochi, K., H. Sato (1986) Transmission of adult T-cell leukemia virus (HTLV-1), through blood transfusion and its prevention. AIDS Res 2: S157-S161.

Pennington, J., G.P. Taylor, J. Sutherland, R.E. Davis, J. Seghatchian, J.P. Allain, L.M. Williamson (2002) Persistence of HTLV-I in blood components after leukocyte depletion. Blood 100: 677-681. stored at room temperature for 15 days or more, is not capable of transmitting HIV, HCV or HBV. Cell Tissue Bank 12: 99-104.

Sanzen, L., A. Carlsson (1997) Transmission of human T-cell lymphotrophic virus type 1 by a deep-frozen bone allograft. Acta Orthop Scand 68: 72-74.

Schon, M.P., T.M. Zollner, W.H. Boehncke (2003) The molecular basis of lymphocyte recruitment to the skin: clues for pathogenesis and selective therapies of inflammatory disorders. J Invest Dermatol 121: 951-962.

US Department of Health and Human Services, Food and Drug Administration (2004) Eligibility determination for donors of human cells, tissues, and cellular and tissue-based products. Fed Regist 69: 29786-29834.

US Department of Health and Human Services, Food and Drug Administration (2007) Final guidance for industry: eligibility determination for donors of human cells, tissues, and cellular and tissue-based products (HCT/Ps). http://www.fda.gov/downloads/BiologicsBloodVaccines/GuidanceComplianceRegulatoryInformation/Guidances/Tissue/ ucm091345.pdf (accessed April 17, 2013). 